\title{
ANALISA PERKUATAN TOWER TELEKOMUNIKASI AKIBAT PENAMBAHAN BEBAN ANTENA
}

\author{
Arief Kusbiantoro \\ Program Studi D3 Teknik Sipil Fakultas Teknik Universitas Pandanaran \\ J1. Banjarsari Barat No. 1 Semarang \\ Email: ariefkusb@gmail.com
}

\begin{abstract}
ABSTRAK
Bertambahnya kemajuan zaman dan meningkatnya kebutuhan masyarakat akan telekomunikasi membuat operator seluler terus meningkatkan layanan, baik layanan dari sisi coverage, kapasitas, ataupun kualitas jaringan. Untuk peningkatan kapasitas ataupun kualitas jaringan bisa dilakukan dengan pemutakhiran perangkat ataupun penambahan perangkat di tower telekomunikasi. Penambahan perangkat bisa dilakukan meliputi penambahan antena sektor ataupun antena transmisi. Penambahan perangkat di tower telekomunikasi membawa akibat berupa bertambahnya beban yang harus dipikul oleh tower telekomunikasi tersebut. Pertambahan beban yang terjadi harus dianalisa, apakah penambahan beban tersebut akan membahayakan stabilitas struktur tower telekomunikasi tersebut.

Pengecekan stabilitas tower telekomunikasi meliputi beberapa hal yaitu : rasio tegangan yang terjadi di elemen tower, goyangan tower, puntiran tower, pergeseran tower, dan reaksi tumpuan yang terjadi. Apabila penambahan perangkat di tower telekomunikasi masih dalam batas kapasitas tower tersebut, penambahan perangkat tidak menjadi masalah. Lain halnya jika penambahan perangkat sudah melebihi ambang batas kapasitas tower, maka hal tersebut akan menjadi masalah. Apabila salah satu dari kriteria di atas ada yang terlewati walau kriteria yang lain aman, struktur tower dianggap tidak aman dan harus dilakukan perhitungan ulang.
\end{abstract}

Kata kunci : beban, kapasitas, stabilitas struktur

\section{PENDAHULUAN}

Meningkatnya kemajuan zaman dan meningkatnya kebutuhan masyarakat mendorong operator penyedia jasa seluler berlomba memberikan pelayanan yang terbaik kepada masyarakat. Peningkatan pelayanan kepada masyarakat bisa bersifat ekonomi ataupun teknologi. Dari sisi ekonomi, operator penyedia jasa telpon seluler berusaha memberikan tarif yang kompetitif dengan berbagai layanan / fitur. Dari sisi teknologi, peyedia jasa layanan telpon seluler berusaha memberikan layanan yang sempurna baik dari sisi cakupan (coverage), kapasitas (capacity), dan kualitas (quality). Untuk penambahan layanan cakupan bisa dilakukan dengan penambahan atau pembangunan tower telekomunikasi baru. Untuk penambahan kapasitas dan kualitas bisa dilakukan dengan mengganti perangkat baru yang lebih canggih ataupun menambah perangkat yang sudah ada. Saat ini menambah perangkat masih menadi salah satu cara yang masih banyak dilakukan oleh beberap operator penyedia jasa seluler. Penambahan perangkat bisa meliputi penambahan perangkat antena sektoral ataupun antena transmisi.

Penambahan perangkat yang dilakukan di tower akan mengakibatkan terjadinya penambahan beban di tower telekomunikasi tersebut. Pada perencanaan awal, tiap-tiap tower sudah didesain dengan kapasitas masing-masing. Secara umum tower telekomunikasi terbagi dalam 3 tipe yaitu tipe ringan (light), tipe sedang (medium), dan tipe berat (heavy). Pembagian tipe tersebut 
berdasar pada kapasitas beban tower yang bisa dipikul. Untuk tower tipe ringan tidak bisa diberi beban sepert tipe sedang atau tipe berat. Karena hal tersebut akan berpengaruh kepada stabilitas tower. Pada tulisan ini akan dibahas tentang efek penambahan perangkat antena sektoral pada tower kaki 4 tinggi 70 m dengan tipe SST ( Self Supporting Tower ). Jadi tidak dilakukan pengecekan pada pondasi tower.

\section{LANDASAN TEORI}

\section{Faktor tekuk}

Adanya faktor tekuk harus diperhatikan dalam perencanaan struktur tower $(\mathrm{kc})$. Faktor ini merupakan kekakuan suatu elemen struktur yang bergantung pada kekangan rotasi dan translasi pada ujung ujung komponen struktur (Salmon, 1996). Faktor kc pada desain kolom sangat berpengaruh terhadap perhitungan kekuatan tekan. Persyaratan yang berlaku seperti dalam persamaan berikut.

$$
\begin{gathered}
\frac{N u}{\phi c \times N n} \geq 0.2 \rightarrow \text { dominan tekan } \\
\frac{N u}{\phi c \times N n}+\frac{8}{9}\left[\frac{M u x}{\phi b \times M n x}+\frac{M u y}{\phi b \times M n y}\right] \leq 1 \\
\frac{N u}{\phi c \times N n} \leq 0.2 \rightarrow \text { dominan lentur } \\
\frac{N u}{2 \times \phi c \times N n}+\left[\frac{M u x}{\phi b \times M n x}+\frac{M u y}{\phi b \times M n y}\right] \leq 1
\end{gathered}
$$

$\mathrm{Nu}=$ beban aksial limit

$\mathrm{Mu}=$ momen ultimit

$\mathrm{Nn}=$ tahanan aksial penampang

$\mathrm{Mn}=$ tahanan aksial mpenampang

$\phi \mathrm{c}=0,85$ ( faktor reduksi tekan )

$\phi b=0,9$ ( faktor reduksi lentur )

\section{Stabilitas}

perencanaan tower telekomunikasi ada beberapa hal yang harus diperhatikan yaitu:

\section{a. Tipe tower.}

Di lapangan ada beberapa tipe tower telekomunikasi yang sudah umum dipakai: self supporting tower, guyed tower, dan monopole. Self supporting tower ( SST ) mempunyai 2 jenis tipe: kaki 3 dan kaki 4 dengan banyak variasi ketinggian, mulai dari ketinggian $20 \mathrm{~m}$ sampai dengan $120 \mathrm{~m}$. Berdasarkan kelas beban tower, SST mempunyai beberapa tipe, yaitu: light, medium, dan heavy. Tipe light diperuntukkan bagi tower telekomunikasi yang berada di lokasi end site dengan beban antena yang relatif lebih kecil. Tipe heavy diperuntukkan bagi tower dengan beban antena yang relatif besar. Di tulisan ini tipe tower yang dipakai adalah tower SST kaki 4 tinggi $70 \mathrm{~m}$ tipe light.

\section{b. Model tower}

Dalam MS Tower ada banyak tipe pilihan untuk model bracing tower (EEC,2018). Dalam tulisan ini model bracing tower yang dipilih adalah XTR1, PL2A.

\section{c. Elemen tower}

Untuk material tower punya beberapa persyaratan yang mengacu pada AISC (2010).

Dimensi siku yang digunakan adalah siku L 45, L 50, L 65, L 70, L 80, L 90, L 100, L 110, L 120, L 130, L 150.

Tabel 1. Spesifikasi material

\begin{tabular}{|l|l|c|c|c|}
\hline Material & Standart & Grade & $\begin{array}{c}\text { Fy } \\
(\mathrm{Mpa})\end{array}$ & $\begin{array}{c}\text { Fu } \\
(\mathrm{Mpa})\end{array}$ \\
\hline $\begin{array}{l}\text { Profil \& } \\
\text { Plat }\end{array}$ & $\begin{array}{l}\text { ASTM } \\
\text { A36 }\end{array}$ & SS400 & 245 & 400 \\
\hline Baut & $\begin{array}{l}\text { ASTM } \\
\text { A325 }\end{array}$ & 8.8 & & 800 \\
\hline Angkur & $\begin{array}{l}\text { ASTM } \\
307\end{array}$ & & 240 & 400 \\
\hline
\end{tabular}

\section{d. Pembebanan Tower}

Beban yang bekerja di tower meliputi : beban mati, beban es, beban angin, beban perlengkapan yang meliputi beban antena, lampu tower, tangga tower (Berman, 2012). Untuk di Indonesia beban es tidak dimasukkan.

\section{Beban Angin}

Pembebanan angin menggunakan dasar EIA / TIA 222F (1996). Dalam perencanaan tower ada 3 kecepatan angin yaitu : kecepatan angin rata-rata per jam, kecepatan puncak tiupan 3 detik, dan kecepatan tertinggi. Hubungan 3 jenis kecapatan di atas sebagai berikut :

Kecepatan tertinggi $=1,25 \mathrm{~s} / \mathrm{d} \quad 1,3$ kali kecepatan angin rata-rata per jam

Kecepatan puncak 3 detik $=1,52$ kali kecepatan angin rata-rata per jam 
Kombinasi beban angin yang digunakan adalah angin dengan kecepatan $120 \mathrm{~km} / \mathrm{jam}$, dengan besaran sudut arah datang angin meliputi : $0^{\circ}$, $45^{\circ}, 90^{\circ}, 135^{\circ}, 180^{\circ}, 225^{\circ}, 270^{\circ}, 315^{\circ}$.

Untuk menghitung beban angin pada tower menggunakan persamaan berikut :

$$
\begin{aligned}
& \mathrm{F}=\mathrm{qz} \times \mathrm{G}_{\mathrm{H}}\left[\mathrm{C}_{\mathrm{F}} \times \mathrm{A}_{\mathrm{E}}+\sum\left(\mathrm{C}_{\mathrm{A}} \times \mathrm{A}_{\mathrm{A}}\right)\right] \\
& \mathrm{F} \leq 2 \times \mathrm{qz} \times \mathrm{G}_{\mathrm{H}} \times \mathrm{A}_{\mathrm{G}}
\end{aligned}
$$

$\mathrm{F}$ = gaya angin horisontal

$\mathrm{A}_{\mathrm{G}}=$ luas kotor dari satu panel jika penampangnya solid

\section{Tekanan kecepatan $\mathrm{qz}$}

$\mathrm{qZ}=0.613 \times \mathrm{K}_{\mathrm{z}} \times \mathrm{V}^{2}$

$\mathrm{K}_{\mathrm{z}}=[\mathrm{Z} / 10]^{2 / 7}$

$1.0 \leq \mathrm{K}_{\mathrm{Z}} \leq 2.58$

$\mathrm{V}=$ kecepatan angin rata2 di lokasi tower

$\mathrm{Z}=$ jarak / ketinggian dari muka tanah ke pertengahan section

\section{Gust response factor $\mathbf{G}_{\mathrm{H}}$}

$$
\begin{gathered}
\mathrm{GH}=0.65+\left(\frac{h}{10}\right)^{1 / 7} \\
1.0 \leq \mathrm{GH} \leq 1.25
\end{gathered}
$$

\section{Koefisien faktor struktur $\mathbf{C}_{\mathbf{F}}$}

$\mathrm{C}_{\mathrm{F}}=4.0 \mathrm{e}^{2}-5.9 \mathrm{e}+4.0$

$\mathrm{e}=$ rasio kepadatan

\section{Luas proyeksi efektif pada satu muka $A_{E}$}

$$
\begin{aligned}
& A_{E}=D_{F} \times A_{F}+D_{R} \times A_{R} \times R_{R} \\
& R_{R}=0.51 \times e^{2}+0.57 \\
& R_{R} \leq 1
\end{aligned}
$$

$\mathrm{A}_{\mathrm{F}}=$ luasan terproyeksi dari komponen

$A_{R}=$ luas terproyeksi dari komponen sruktural pada satu muka penampang

$\mathrm{D}_{\mathrm{F}} \& \mathrm{D}_{\mathrm{R}}=$ faktor arah angin komponen datar, lingkaran

$\mathrm{C}_{\mathrm{A}}=$ koefisien gaya appurtenance linier

Untuk menghitung beban angin pada antena menggunakan persamaan berikut :

$$
\begin{aligned}
& F_{A}=C_{A} \times A \times K_{Z} \times G_{H} \times V^{2} \\
& F_{S}=C_{S} \times A \times K_{Z} \times G_{H} \times V^{2} \\
& M=C_{M} \times A \times D \times K_{Z} \times G_{H} \times V^{2} \\
& F_{A}=\text { Gaya Aksial } \\
& F_{S}=\text { Gaya samping } \\
& M=\text { Momen puntir } \\
& C_{A}=\text { Koefisien gaya aksial sejajar antena }
\end{aligned}
$$

\begin{tabular}{|c|c|c|c|c|}
\hline No & Type & Jumlah & Tinggi & Keterangan \\
\hline 1 & RBS 1 & 6 & 70 & Existing \\
\hline 2 & RBS 2 & 3 & 56.5 & Existing \\
\hline 3 & $\begin{array}{l}\text { MW } \phi \\
0.6 \mathrm{~m}\end{array}$ & 1 & 33 & Existing \\
\hline 4 & RBS 3 & 3 & 50 & Penambahan \\
\hline
\end{tabular}

$\mathrm{C}_{\mathrm{M}}=$ koefisien beban angin untuk gaya momen

$\mathrm{C}_{\mathrm{S}}=$ Koefisien gaya aksial tegak lurus antena

$\mathrm{V}=$ Kecepatan angin

$\mathrm{A}=$ Luas proyeksi normal dari antena

$\mathrm{D}=$ diameter antena

$\mathrm{K}_{\mathrm{Z}}=$ Koefisien keterbukaan struktur

Tabel 2. Beban Antena

\begin{tabular}{|c|l|c|c|c|}
\hline No & Type & Jumlah & $\begin{array}{c}\text { Berat } \\
\text { Satuan }\end{array}$ & $\begin{array}{c}\text { Berat } \\
\text { Total }\end{array}$ \\
\hline 1 & RBS & 12 & 70 & 840 \\
\hline 2 & MW $\phi 0.6 \mathrm{~m}$ & 1 & 33 & 33 \\
\hline
\end{tabular}

\section{METODOLOGI}

Dalam penelitian ini, perhitungan struktur tower menggunakan program komputer MS Tower. Tinggi tower yang digunakan adalah tower $70 \mathrm{~m}$ dengan tipe light, dengan model bracing yang dipilih adalah tipe XTR1 untuk bracing vertikal, PL2A dan PP4 untuk bracing horisontal. Untuk bentuk bracing bisa dilihat seperti gambar berikut.

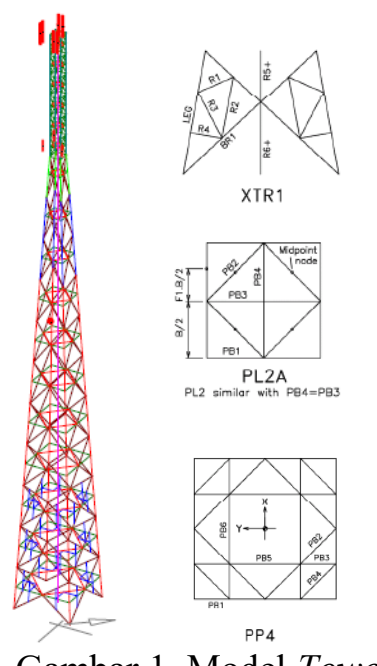

Gambar 1. Model Tower

\section{Kombinasi Beban}

Untuk kombinasi beban yang digunakan seperti persamaan berikut : 
Tabel 3. Kombinasi beban angin

\begin{tabular}{|c|c|c|c|c|}
\hline Kombinasi & DL & WL & Arah & Kecepatan \\
\hline 1 & 1.1 & 1.0 & $0^{\circ}$ & $120 \mathrm{~km} / \mathrm{jam}$ \\
\hline 2 & 1.1 & 1.0 & $45^{\circ}$ & $120 \mathrm{~km} / \mathrm{jam}$ \\
\hline 3 & 1.1 & 1.0 & $90^{\circ}$ & $120 \mathrm{~km} / \mathrm{jam}$ \\
\hline 4 & 1.1 & 1.0 & $135^{\circ}$ & $120 \mathrm{~km} / \mathrm{jam}$ \\
\hline 5 & 1.1 & 1.0 & $180^{\circ}$ & $120 \mathrm{~km} / \mathrm{jam}$ \\
\hline 6 & 1.1 & 1.0 & $225^{\circ}$ & $120 \mathrm{~km} / \mathrm{jam}$ \\
\hline 7 & 1.1 & 1.0 & $270^{\circ}$ & $120 \mathrm{~km} / \mathrm{jam}$ \\
\hline 8 & 1.1 & 1.0 & $315^{\circ}$ & $120 \mathrm{~km} / \mathrm{jam}$ \\
\hline 9 & 1.0 & 1.0 & $0^{\circ}$ & $120 \mathrm{~km} / \mathrm{jam}$ \\
\hline 10 & 1.0 & 1.0 & $45^{\circ}$ & $120 \mathrm{~km} / \mathrm{jam}$ \\
\hline 11 & 1.0 & 1.0 & $90^{\circ}$ & $120 \mathrm{~km} / \mathrm{jam}$ \\
\hline 12 & 1.0 & 1.0 & $135^{\circ}$ & $120 \mathrm{~km} / \mathrm{jam}$ \\
\hline 13 & 1.0 & 1.0 & $180^{\circ}$ & $120 \mathrm{~km} / \mathrm{jam}$ \\
\hline 14 & 1.0 & 1.0 & $225^{\circ}$ & $120 \mathrm{~km} / \mathrm{jam}$ \\
\hline 15 & 1.0 & 1.0 & $270^{\circ}$ & $120 \mathrm{~km} / \mathrm{jam}$ \\
\hline 16 & 1.0 & 1.0 & $315^{\circ}$ & $120 \mathrm{~km} / \mathrm{jam}$ \\
\hline 17 & 1.05 & 0.49 & $0^{\circ}$ & $84 \mathrm{~km} / \mathrm{jam}$ \\
\hline 18 & 1.05 & 0.49 & $45^{\circ}$ & $84 \mathrm{~km} / \mathrm{jam}$ \\
\hline 19 & 1.05 & 0.49 & $90^{\circ}$ & $84 \mathrm{~km} / \mathrm{jam}$ \\
\hline 20 & 1.05 & 0.49 & $135^{\circ}$ & $84 \mathrm{~km} / \mathrm{jam}$ \\
\hline 21 & 1.05 & 0.49 & $180^{\circ}$ & $84 \mathrm{~km} / \mathrm{jam}$ \\
\hline 22 & 1.05 & 0.49 & $225^{\circ}$ & $84 \mathrm{~km} / \mathrm{jam}$ \\
\hline 23 & 1.05 & 0.49 & $270^{\circ}$ & $84 \mathrm{~km} / \mathrm{jam}$ \\
\hline 24 & 1.05 & 0.49 & $315^{\circ}$ & $84 \mathrm{~km} / \mathrm{jam}$ \\
\hline & & & & \\
\hline
\end{tabular}

Keterangan:

$\mathrm{DL}=$ Beban tower

$\mathrm{WL}=$ Beban angin

\section{Beban Antena}

Untuk beban antena seperti tabel 1 .

Tabel 4. Beban antena awal

\begin{tabular}{|c|c|c|l|}
\hline Tipe Antena & Jumlah & Ketinggian & Arah \\
\hline MW 1.2 m & 1 & 33 & $260^{\circ}$ \\
\hline GSM 1,3m & 3 & 56 & $\begin{array}{l}40^{\circ} / 120^{\circ} / \\
220^{\circ}\end{array}$ \\
\hline & & & $\begin{array}{l}40^{\circ} / 220^{\circ} / \\
130^{\circ} / 310^{\circ} / \\
220^{\circ} / 40^{\circ}\end{array}$ \\
\hline
\end{tabular}

Data masukan dalam MS Tower secara garis besar meliputi 2 bagian yaitu :

\section{a. Data geometri}

Data yang harus dimasukkan dalam bagian ini meliputi : judul, satuan, jumlah sisi, lebar sisi bawah tower, ketinggian base plat dari muka tanah.

TITL1 SITE

TITL2

UNITS 1

PROFILE

FACES 4

WBASE 6.90

RLBAS 0.0000

PANEL 100 HT 0.00 TW 1.30

FACE X LEG 0 BR1 0 H1 3 R1 0

PLAN PL2A PB1 3 PB2 2 PB3 0 PB4 0

PANEL 1 HT 2.50 TW 1.30

FACE X LEG 6 BR1 3 H1 3 R1 0

PLAN PL2A PB1 3 PB2 2 PB3 0 PB4 0 XIP

PANEL 2 HT 2.50 TW 1.30

FACE X LEG 6 BR 13 H1 3 R 10

PLAN PL2A PB1 3 PB2 2 PB3 0 PB4 0 XIP

PANEL 3 HT 2.50 TW 1.30

FACE X LEG 6 BR1 3 H1 3 R1 0

PLAN PL2A PB1 3 PB2 2 PB3 0 PB4 0 XIP

PANEL 4 HT $2.50 \mathrm{TW} 1.30$

FACE X LEG 6 BR1 3 H1 3 R1 0

PLAN PL2A PB1 3 PB2 2 PB3 0 PB4 0 XIP

PANEL 5 HT 2.50 TW 1.30

FACE X LEG 6 BR 13 H1 3 R 10

PLAN PL2A PB1 3 PB2 2 PB3 0 PB4 0 XIP

PANEL 6 HT 2.50 TW 1.30

FACE X LEG 6 BR1 3 H1 3 R1 0

PLAN PL2A PB1 3 PB2 2 PB3 0 PB4 0 XIP

PANEL 7 HT 5.00 TW 1.30

FACE X LEG 9 BR 15 H1 3 R 10

PLAN PL2A PB1 3 PB2 2 PB3 0 PB4 0 XIP

PANEL 8 HT 5.00

FACE X LEG 10 BR 15 H1 0 R1 0

PLAN PL2A PB1 3 PB2 2 PB3 0 PB4 0 XIP 
PANEL 9 HT 5.00

FACE X LEG 10 BR 15 H1 0 R1 0

PLAN PL2A PB1 3 PB2 2 PB3 0 PB4 0 XIP

PANEL 10 HT 5.00

FACE X LEG 11 BR1 5 H1 0 R1 0

PLAN PL2A PB1 3 PB2 2 PB3 0 PB4 0 XIP

PANEL 11 HT 5.00

FACE X LEG 11 BR 15 H1 0 R 10

PLAN PL2A PB1 3 PB2 2 PB3 0 PB4 0 XIP

PANEL 12 HT 5.00

FACE X LEG 11 BR1 5 H1 0 R1 0

PLAN PL2A PB1 3 PB2 2 PB3 0 PB4 0 XIP

PANEL 13 HT 5.00

FACE X LEG 11 BR1 5 H1 0 R1 0

PLAN PL2A PB1 3 PB2 2 PB3 0 PB4 0 XIP

PANEL 14 HT 5.00

FACE X LEG 11 BR 15 H1 0 R1 0

PLAN PL2A PB1 3 PB2 2 PB3 0 PB4 0 XIP

PANEL 15 HT 5.00

FACE XM3D LEG 11 BR1 5 R1 2 R2 2 R3 2 R4 2 R5 1

PLAN PP4 PB1 3 PB2 2 PB3 1 PB4 0 PB5 0 PB6 0 XIP

PANEL 16 HT 5.00

FACE XM3D LEG 11 BR1 5 R1 2 R2 2 R3 2 R4 2 R5

$$
1
$$

PLAN PP4 PB1 3 PB2 2 PB3 1 PB4 0 PB5 0 PB6 0 XIP

PANEL 17 HT 5.00

FACE XM3D LEG 11 BR1 5 R1 2 R2 2 R3 2 R4 2 R5

$$
1
$$

PLAN PP4 PB1 3 PB2 2 PB3 1 PB4 0 PB5 0 PB6 0 XIP

END

SECTIONS

LIBR P:UK IFACT 0.1

1 EA40X40X4 $\square \square$ Y FY 245 BH 17.5

2 EA50X50X5 $\square \square$ Y FY 245 BH 17.5

3 EA60X60X6 $\square \square$ Y FY 245 BH 17.5

4 EA65X65X6 $\square \square$ Y FY 245 BH 17.5

5 EA70X70X7 $\square$ Y FY 245 BH 17.5

6 EA80X80X8 $\square$ Y FY 245 BH 17.5

7 EA90X90X9 $\square$ Y FY 245 BH 17.5

8 EA100X100X10 $\square$ Y FY 245 BH 17.5

9 EA120X120X12 $\square$ Y FY 245 BH 17.5
10 EA130X130X12 Y FY 245 BH 17.5

11 EA150X150X15 $\square$ Y FY 245 BH 17.5

END

END

b. Data pembebanan

Data yang dimasukkan dalam bagian ini meliputi : standar perencanaan yang dipakai, kombinasi beban angin, data material tower dan data antena.

PARAMETERS

CODE EIA222

ANGN 130

VB 33.33

RHO 1.16

GRAV $\square 9.8$

OVERLAP 1

END

LOADS

CASE 100 TOWER WEIGHT ONLY

DL

CASE 200 FACE WIND 0

WL ANGLE 0 NOICE

CASE 210 FACE WIND 45

L ANGLE 45 NOICE

CASE 220 FACE WIND 90

WL ANGLE 90 NOICE

CASE 230 FACE WIND 135

WL ANGLE 135 NOICE

CASE 240 FACE WIND 180 WL ANGLE 180 NOICE

CASE 250 FACE WIND 225

WL ANGLE 225 NOICE

CASE 260 FACE WIND 270

WL ANGLE 270 NOICE

CASE 270 FACE WIND 315

WL ANGLE 315 NOICE

CASE 300 DL + WIND 0, MAXIMUM

COMPRESSION

COMBIN 1001.1

COMBIN 2001.0 
CASE 310 DL + WIND 45, MAXIMUM

COMPRESSION

COMBIN 1001.1

COMBIN 2101.0

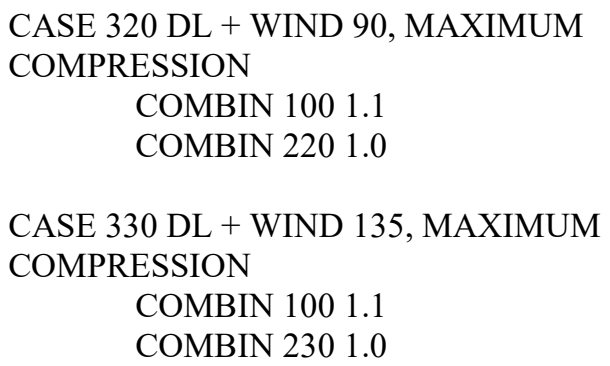

CASE 440 DL + WIND 180, MAXIMUM TENSION

COMBIN 1001.0

COMBIN 2401.0

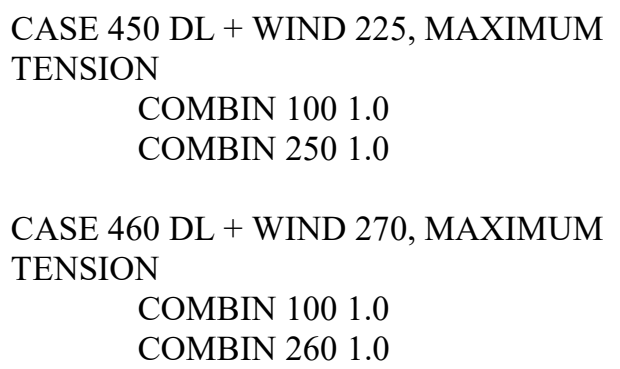

CASE 470 DL + WIND 315, MAXIMUM TENSION

COMBIN 1001.0 COMBIN 2701.0

CASE $500 \mathrm{DL}+$ WIND $0,84 \mathrm{KM} / \mathrm{H}$ OPERASIONAL REQ. COMBIN 1001.05 COMBIN $2000.49 \$(84 / 120)^{\wedge} 2$

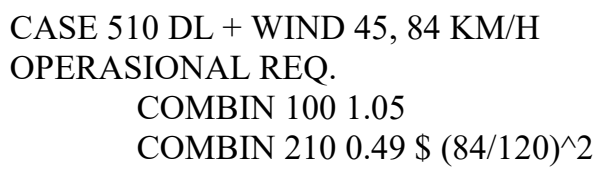

CASE 540 DL + WIND 180, $84 \mathrm{KM} / \mathrm{H}$ OPERASIONAL REQ.

COMBIN 1001.05

COMBIN $2400.49 \$(84 / 120)^{\wedge} 2$

CASE $550 \mathrm{DL}+$ WIND 225, $84 \mathrm{KM} / \mathrm{H}$ OPERASIONAL REQ.

COMBIN 1001.05

COMBIN $2500.49 \$(84 / 120)^{\wedge} 2$

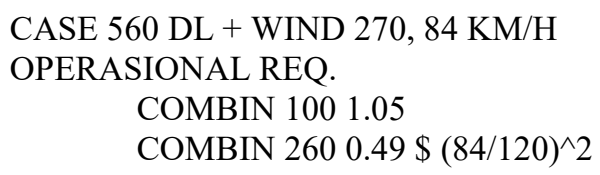


CASE $570 \mathrm{DL}+$ WIND $315,84 \mathrm{KM} / \mathrm{H}$

OPERASIONAL REQ.

COMBIN 1001.05

COMBIN $2700.49 \$(84 / 120)^{\wedge} 2$

END

ANCILLARIES

LINEAR LIBR P:Ms_Lin

\$ Ladder \& Cable Ladder

LADDER XB 0.00 YB 0.00 ZB 0.00 XT 0.00

YB 0.00 ZT 70.00 LIB H-LADDER FACT 1

ANG 0

C-LADDER XB 0.00 YB $0.00 \mathrm{ZB} 0.00 \mathrm{XT}$

0.00 YB 0.00 ZT 70.00 LIB C-LADDER

FACT 1 ANG 0

FEEDER1 XB 0.00 YB 0.00 ZB 3.00 XT 0.00

YB 0.00 ZT 70.00 LIB FDR20 FACT 12

ANG 0

FEEDER2 XB 0.05 YB 0.00 ZB 3.00 XT 0.05

YB 0.00 ZT 56.50 LIB FDR20 FACT 6 ANG 0

FEEDER3 XB 0.10 YB 0.00 ZB 3.00 XT 0.10 YB 0.00 ZT 33.00 LIB FDR10 FACT 1 ANG 0

FEEDER4 XB 0.15 YB 0.00 ZB 3.00 XT 0.15 YB 0.00 ZT 50.00 LIB FDR20 FACT 6 ANG 0 \$ FOR 3G

LARGE LIBR P:Ms Anc

$\$$ Existing antenna

\$ RF Antenna

RBS-1 XA 1.65 YA 0.90 ZA 70.00 LIB

GSM2.6 ANG 40 AMASS 40.

RBS-2 XA 1.65 YA 0.40 ZA 70.00 LIB

GSM2.6 ANG 220 AMASS 40.

RBS-3 XA 0.90 YA -1.65 ZA 70.00 LIB

GSM2.6 ANG 130 AMASS 40.

RBS-4 XA 0.40 YA -1.65 ZA 70.00 LIB

GSM2.6 ANG 310 AMASS 40.

RBS-5 XA -1.65 YA -0.90 ZA 70.00 LIB

GSM2.6 ANG 220 AMASS 40.

RBS-6 XA -1.65 YA -0.40 ZA 70.00 LIB

GSM2.6 ANG 40 AMASS 40

RBS-7 XA 1.18 YA 1.18 ZA 56.50 LIB

GSM1.3 ANG 40 AMASS 40.

RBS-8 XA 1.18 YA -1.18 ZA 56.50 LIB

GSM1.3 ANG 130 AMASS 40.

RBS-9 XA -1.18 YA -1.18 ZA 56.50 LIB

GSM1.3 ANG 220 AMASS 40.

\$ MW Antenna
MW-1 XA -1.90 YA -1.90 ZA 33.00 LIB

SH1PR-2 ANG 260 AMASS 40.

$\$$

\$ Proposed antenna

\$ RF Antenna

3G-1 XA 1.905 YA 0.905 ZA 50.00 LIB

GSM1.3 ANG 50 AMASS 40.

3G-2 XA 1.905 YA -0.905 ZA 50.00 LIB

GSM1.3 ANG 120 AMASS 40.

3G-3 XA -1.905 YA -0.905 ZA 50.00 LIB

GSM1.3 ANG 240 AMASS 40.

END

END

END

\section{HASIL DAN PEMBAHASAN}

Untuk kondisi beban awal seperti di atas, hasil perhitungan strukturnya sebagai berikut.

Tabel 5. Rasio Tegangan awal

\begin{tabular}{|l|c|c|c|c|}
\hline \multicolumn{5}{|c|}{ Rasio Tegangan Terjadi } \\
\hline Description & Output & & Limitation & Note \\
\hline Leg & 0.925 & $\leq$ & 1 & OK \\
\hline Bracing & 0.867 & $\leq$ & 1 & OK \\
\hline Horizontal & 0.026 & $\leq$ & 1 & OK \\
\hline
\end{tabular}

Tabel 6. Gaya Reaksi awal

\begin{tabular}{|c|l|l|}
\hline \multicolumn{3}{|c|}{ Reaksi Maksimum } \\
\hline \multirow{4}{*}{ Tarik } & FX $(\mathrm{kN})$ & -55.158 \\
\cline { 2 - 3 } & $\mathrm{FY}(\mathrm{kN})$ & -52.435 \\
\cline { 2 - 3 } & $\mathrm{FZ}(\mathrm{kN})$ & -738.264 \\
\hline \multirow{4}{*}{ Tekan } & $\mathrm{FX}(\mathrm{kN})$ & -49.112 \\
\cline { 2 - 3 } & $\mathrm{FY}(\mathrm{kN})$ & -46.930 \\
\cline { 2 - 3 } & $\mathrm{FZ}(\mathrm{kN})$ & 646.862 \\
\hline
\end{tabular}

Sehubungan dengan adanya rencana peningkatan layanan $3 \mathrm{G}$ di area coverage tower, rencana akan ditambah perangkat antena sektoral $3 \mathrm{G}$, sehingga kondisi beban tower sebagai berikut : 
Tabel 7. Tabel antena tambahan

\begin{tabular}{|c|c|c|c|}
\hline Tipe Antena & Jumlah & Tinggi & Arah \\
\hline MW dia $1.2 \mathrm{~m}$ & 1 & 33 & $260^{\circ}$ \\
\hline GSM $1.3 \mathrm{~m}$ & 3 & 56 & $\begin{array}{c}40^{\circ} / 120^{\circ} / \\
220^{\circ}\end{array}$ \\
\hline GSM 2.6 m & 6 & 70 & $\begin{array}{c}40^{\circ} / 220^{\circ} / \\
130^{\circ} / 310^{\circ} / \\
220^{\circ} / 40^{\circ}\end{array}$ \\
\hline $3 \mathrm{G} 1.3 \mathrm{~m}$ & 3 & 50 & $\begin{array}{c}50 / 120 / \\
240\end{array}$ \\
\hline
\end{tabular}

Dari penambahan beban antena mengakibatkan adanya perubahan hasil perhitungan struktur sebagai berikut :

Tabel 8. Tabel rasio tegangan setelah penambahan antena

\begin{tabular}{|l|c|c|c|c|}
\hline \multicolumn{5}{|c|}{ Rasio Tegangan Terjadi } \\
\hline Description & Output & & Limitation & Note \\
\hline Leg & 1.162 & $>$ & 1 & NOK \\
\hline Bracing & 0.910 & $\leq$ & 1 & OK \\
\hline Horizontal & 0.027 & $\leq$ & 1 & OK \\
\hline
\end{tabular}

Tabel 9. displacement awal

\begin{tabular}{|c|c|c|l|c|}
\hline \multicolumn{5}{|c|}{ Puntiran, Goyangan, dan Lendutan } \\
\hline Description & Output & & Limitation & Note \\
\hline Rotasi maks X & $0.4094^{\circ}$ & $\leq$ & $0.5^{\circ}$ & OK \\
\hline Rotasi maks Y & $0.4094^{\circ}$ & $\leq$ & $0.5^{\circ}$ & OK \\
\hline Rotasi maks Z & $0.0286^{\circ}$ & $\leq$ & $0.5^{\circ}$ & OK \\
\hline Goyangan maks & $0.0286^{\circ}$ & $\leq$ & $0.5^{\circ}$ & OK \\
\hline Lendutan Maks & $0.2371 \mathrm{~m}$ & $\leq$ & $0.7 \mathrm{~m}$ & OK \\
\hline
\end{tabular}

Tabel 10. Tabel displacement setelah penambahan antenna

\begin{tabular}{|c|c|c|c|c|}
\hline \multicolumn{5}{|c|}{ Puntiran, Goyangan, dan Lendutan } \\
\hline Description & Output & & Limitation & Note \\
\hline Rotasi maks X & $0.4042^{\circ}$ & $\leq$ & $0.5^{\circ}$ & OK \\
\hline Rotasi maks Y & $0.4042^{\circ}$ & $\leq$ & $0.5^{\circ}$ & OK \\
\hline Rotasi maks Z & $0.0278^{\circ}$ & $\leq$ & $0.5^{\circ}$ & OK \\
\hline Goyangan maks & $0.0278^{\circ}$ & $\leq$ & $0.5^{\circ}$ & OK \\
\hline Lendutan Maks & $0.2324 \mathrm{~m}$ & $\leq$ & $0.7 \mathrm{~m}$ & OK \\
\hline
\end{tabular}

Tabel 11. Tabel Reaksi setelah penambahan antena

\begin{tabular}{|c|c|c|}
\hline \multicolumn{3}{|c|}{ Reaksi Maksimum } \\
\hline \multirow{4}{*}{ Tarik } & FX ( kN $)$ & -57.068 \\
\cline { 2 - 3 } & FY ( kN $)$ & -54.191 \\
\cline { 2 - 3 } & FZ ( kN $)$ & -761.189 \\
\hline \multirow{4}{*}{ Tekan } & FX ( kN $)$ & -50.916 \\
\cline { 2 - 3 } & FY ( kN $)$ & -48.656 \\
\cline { 2 - 3 } & FZ ( kN $)$ & 668.384 \\
\hline
\end{tabular}

Dari hasil analisa perhitungan diketahui bahwa rasio tegangan maksimum yang terjadi di leg melebihi batas masksimumnya, sehingga akan terjadi kegagalan struktur di leg tower.

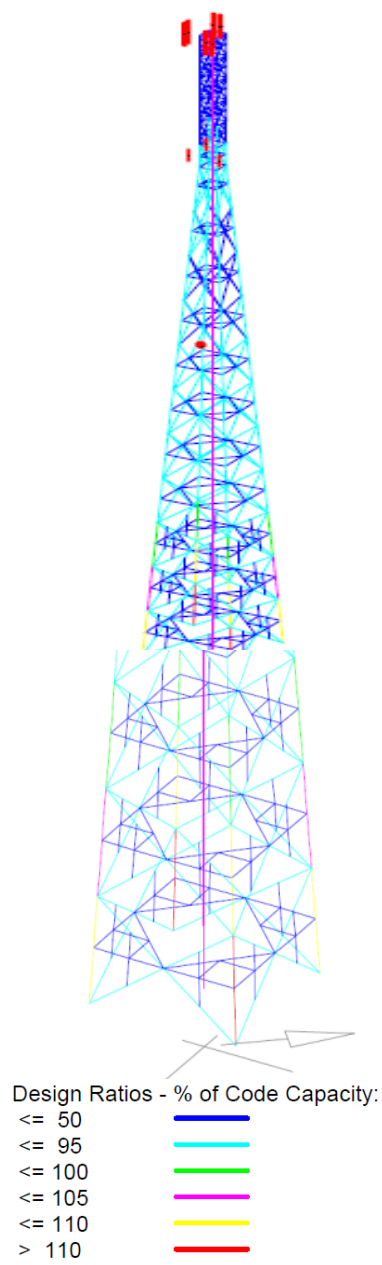

Gambar 2. Kapasitas penampang awal 
Dari gambar rasio tegangan di atas, diketahui bahwa 2 leg terbawah mempunyai rasio tegangan di atas $110 \%$, 2 leg terbawah yang lain mempunyai rasio tegangan antar $105 \%-110 \%$. Untuk leg urutan 2 dari bawah, 2 leg mempunyai rasio tegangan antara $105 \%-110 \%$ dan 2 leg yang lain mempunyai rasio tegangan $100 \%-105 \%$.

Untuk leg urutan 3 dari bawah, semua leg mempunyai rasio tegangan antara rasio tegangan $95 \%-100 \%$.

Sehingga rencana perkuatan yang akan dilakukan hanya ketiga leg terbawah. Berikut gambar struktur tower sebelum dan sesudah perkuatan.
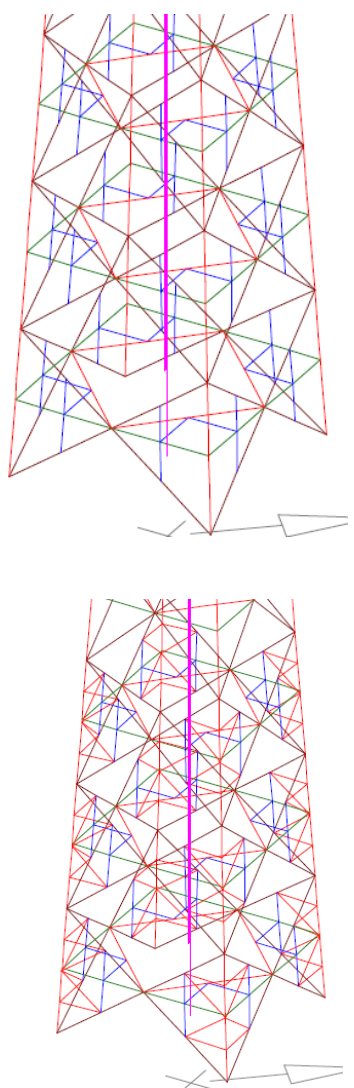

Gambar 3. Gambar Perkuatan

Setelah dilakukan perkuatan dengan cara penambahan bracing pada 3 leg terbawah, hasil perhitungan MS Tower sebagai berikut. Dari gambar di bawah dapat dilhat bahwa semua elemen tower di 3 leg terbawah mempunyai rasio penampang kurang dari $95 \%$.
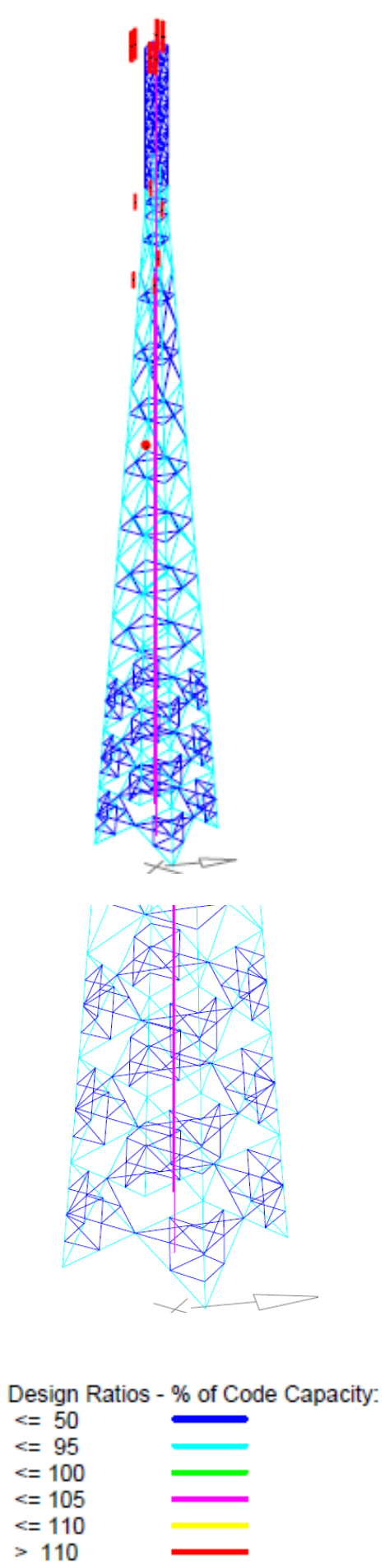

Gambar 4. Kapasitas penampang setelah perkuatan 
Tabel 12. Tabel Rasio tegangan setelah perkuatan

\begin{tabular}{|l|c|c|c|c|}
\hline \multicolumn{5}{|c|}{ Rasio Tegangan Terjadi } \\
\hline Elemen & Hasil & & Batas & Ket \\
\hline Leg & 0.944 & $\leq$ & 1 & OK \\
\hline Bracing & 0.937 & $\leq$ & 1 & OK \\
\hline Horizontal & 0.032 & $\leq$ & 1 & OK \\
\hline
\end{tabular}

Tabel 13. Tabel displacement setelah perkuatan

\begin{tabular}{|c|c|c|c|c|}
\hline \multicolumn{5}{|c|}{ Puntiran, Goyangan, dan Lendutan } \\
\hline Keterangan & Output & & Batas & Ket \\
\hline Rotasi maks X & $0.4093^{\circ}$ & $\leq$ & $0.5^{\circ}$ & OK \\
\hline Rotasi maks Y & $0.4093^{\circ}$ & $\leq$ & $0.5^{\circ}$ & OK \\
\hline Rotasi maks Z & $0.0286^{\circ}$ & $\leq$ & $0.5^{\circ}$ & OK \\
\hline Goyangan maks & $0.0286^{\circ}$ & $\leq$ & $0.5^{\circ}$ & OK \\
\hline Lendutan Maks & $0.2359 \mathrm{~m}$ & $\leq$ & $0.7 \mathrm{~m}$ & OK \\
\hline
\end{tabular}

Untuk gambar detail perkuatan bracing dapat dilihat seperti gambar di bawah, sebagai contoh diambil untuk leg terbawah.
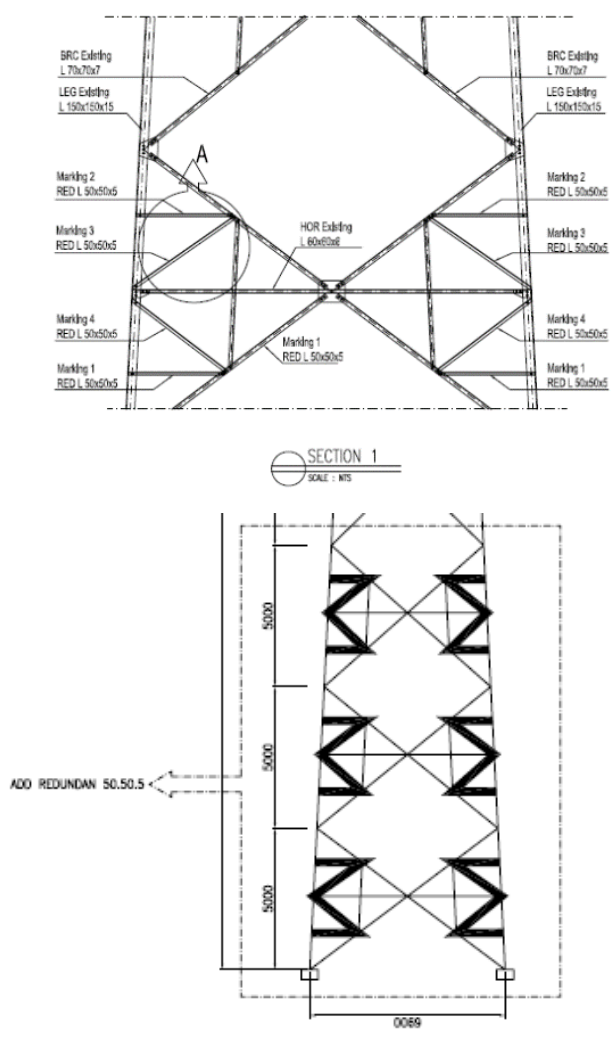

Gambar 5. detail perkuatan

\section{KESIMPULAN}

Bahwa 2 leg terbawah mempunyai rasio tegangan di atas $110 \%, 2$ leg terbawah yang lain mempunyai rasio tegangan antar 105\% - 110\%. Untuk leg urutan 2 dari bawah, 2 leg mempunyai rasio tegangan antara $105 \%-110 \%$ dan 2 leg yang lain mempunyai rasio tegangan $100 \%-105 \%$. Sehingga rencana perkuatan yang akan dilakukan hanya ketiga leg terbawah.

Setelah dilakukan perkuatan dapat dilhat bahwa semua elemen tower di 3 leg terbawah mempunyai rasio penampang kurang dari $95 \%$.

\section{DAFTAR PUSTAKA}

AISC committee, 2010, Specification for Structural Steel Building, ANSI/AISC 36010, AISC, Chicago.

Berman, G. S., 2012, Structural Steel Design and Construction, Greyhawk North America LLC, California.

Engineering Department of EIA, 1996, Structural Standards for Steel Antenna Towers and Antenna Supporting Structures (TIA/EIA222-F), EIA, USA.

Engineering System (EEC) limited, 2008, MStower V6 User's Manual, Engineering System (EEC) limited, England.

Gunawan, R., 2003, Tabel Profil Konstruksi Baja, Penerbit Kanisius, Yogyakarta.

Salmon, Charles G. 1996. Steel Structures: Design and Behaviour Emphasizing Load and Resistance Factor Design Fourth Edition. Harper Collins College Publishers, New York. 